\title{
MicroRNA-362 induces cell proliferation and apoptosis resistance in gastric cancer by activation of NF-KB signaling
}

Jin-tang Xia ${ }^{1,3}$, Lian-zhou Chen², Wei-hua Jian ${ }^{3}$, Ke-Bing Wang ${ }^{2}$, Yong-zhen Yang ${ }^{3}$, Wei-ling He ${ }^{4}$, Yu-long He ${ }^{4}$, De Chen ${ }^{1 *}$ and Wen $\mathrm{Li}^{2^{*}}$

\begin{abstract}
Background: According to cancer-related microRNA (miRNA) expression microarray research available in public databases, miR-362 expression is elevated in gastric cancer. However, the expression and biological role of miR-362 in gastric progression remain unclear.

Methods: miR-362 expression levels in gastric cancer tissues and cell lines were determined using real-time PCR. The roles of miR-362, in promoting gastric cancer cell proliferation and apoptosis resistance, were assessed by different biological assays, such as colony assay, flow cytometry and TUNEL assay. The effect of miR-362 on NF-kB activation was investigated using the luciferase reporter assay, fluorescent immunostaining.

Results: MiR-362 overexpression induced cell proliferation, colony formation, and resistance to cisplatin-induced apoptosis in BGC-823 and SGC-7901 gastric cancer cells. MiR-362 increased NF-kB activity and relative mRNA expression of NF-KB-regulated genes, and induced nuclear translocation of p65. Expression of the tumor suppressor CYLD was inhibited by miR-362 in gastric cancer cells; miR-362 levels were inversely correlated with CYLD expression in gastric cancer tissue. MiR-362 downregulated CYLD expression by binding its 3' untranslated region. NF-kB activation was mechanistically associated with siRNA-mediated downregulation of CYLD. MiR-362 inhibitor reversed all the effects of miR-362.
\end{abstract}

Conclusion: The results suggest that miR-362 plays an important role in repressing the tumor suppressor CYLD and present a novel mechanism of miRNA-mediated NF-KB activation in gastric cancer.

Keywords: miR-362, NF-KB, CYLD, Gastric cancer, Proliferation, Apoptosis

\section{Background}

Gastric cancer is the fourth most common cancer and the second leading cause of cancer death worldwide [1]. Surgery is the main treatment for operable gastric cancer; however, recurrence and metastasis are very common $[2,3]$. The combination of surgery and chemotherapy has recently emerged as an effective strategy for gastric cancer therapy, improving disease-free survival and reducing the risk of recurrence and metastasis as compared with

\footnotetext{
* Correspondence: drchende@gzmc.edu.cn; liwen@mail.sysu.edu.cn 'Department of General Surgery, The third Affiliated Hospital, Guangzhou Medical University, \#63 Duobao Road, Guangzhou, Guangdong 510150, China

${ }^{2}$ Laboratory of General Surgery, The First Affiliated Hospital, Sun Yat-sen University, \#58 Zhongshan er Road, Guangzhou, Guangdong 510080, China Full list of author information is available at the end of the article
}

surgery only in multiple trials $[4,5]$. However, clinical responses to chemotherapy vary greatly, which leads to different curative effects for gastric cancer patients [6]. Although anti-cancer drugs generally kill tumor cells by inducing apoptosis, recent advances have shown that most solid tumors are generally or particularly resistant to chemotherapy-induced apoptosis [7-9]. Therefore, the chemotherapy drug susceptibility of cancer cells with one or more gene mutations and apoptosis pathway defects directly influences the curative effects.

NF- $\mathrm{KB}$ is constitutively elevated in many human tumors, both hematological and solid [10], including gastric cancer [11]. Many studies have shown that activated NF- $\kappa B$ signaling is highly associated with tumorigenesis, tumor progression, and therapy resistance. It plays an 
important role in oncogenesis due to its anti-apoptosis and pro-proliferation activities [12-15]. Many observations indicate that NF- $\mathrm{kB}$ suppresses apoptosis through transcriptional regulation of the expression of anti-apoptotic genes, including TRAF1, TRAF2, c-IAP1, and c-IAP2, which blocks caspase- 8 activation, and the Bcl-2 homologues A1/Bfl-1, Bcl-xL, IEX-1, and XIAP [12]. Over the years, much progress has been made in the study of the regulatory mechanisms of NF- $\mathrm{kB}$ signaling. Ubiquitin modification has been proven to play a crucial role in NF- $\mathrm{kB}$ signaling activation [16-18]. Conversely, ubiquitin deconjugation mediated by deubiquitinases such as CYLD negatively regulates NF- $\mathrm{kB}$ signaling $[19,20]$. CYLD abrogates the activation of NF- $\mathrm{KB}$ signaling via its deubiquitinating activity on multiple NF- $\mathrm{kB}$ signaling mediators, including TRAF2, TRAF6, RIP1, TAK1, NEMO, and BCL3 [21-23]. Furthermore, multiple studies have demonstrated that CYLD is a tumor suppressor associated with the inhibition of cell proliferation and induction of apoptosis $[24,25]$. In hepatocellular carcinoma cells, CYLD downregulation leads to apoptosis resistance [26].

It has been demonstrated that aberrant microRNA (miRNA) expression is associated with various diseases and cancers [27]. Recent evidence revealed that miRNA expression significantly correlates with the progression and prognosis of gastric cancer [28]. In gastric cancer patients, upregulated miR-20b, miR-142-5p, miR-150, and miR-375, and decreased miR-124a, miR-125a-5p, miR$146 \mathrm{a}$, and miR-45 were associated with shorter survival times [29]. Several miRNAs appear to predict or affect the response to chemotherapy. MiR-15b or miR-16 overexpression increases gastric cancer cell sensitivity to vincristine, whereas miR-15b or miR-16 downregulation increases gastric cell sensitivity to related drugs [30].

From public databases and datasets on gastric cancerrelated miRNA expression microarray, we found that miR-362 is upregulated in gastric cancer. Though miR362 was reported to be upregulated in acral melanomas as compared to non-acral melanomas [31], the function and mechanism of miR-362 in gastic cancer remains unknown. In the present study, we found that miR-362 was significantly associated with cell proliferation and apoptosis resistance of gastric cancer. Moreover, miR-362 activated NF- $\mathrm{KB}$ signaling through directly targeting of the $3^{\prime}$ untranslated region (3'-UTR) and suppression of CYLD in human gastric cancer cells. Thus, our results suggest that miR-362 might play an important role in promoting the development and progression of gastric cancer.

\section{Materials and methods Cell culture}

Primary normal human gastric epithelial cells (NGEC) were established from gastric biopsy specimens obtained from upper gastrointestinal endoscopy and cultured as described previously [32]. The gastric cancer cell lines SGC7901, BGC-823, HGC-27, MKN-28, and MGC-803 were maintained in DMEM (Invitrogen, Carlsbad, CA, USA) supplemented with $10 \%$ fetal bovine serum (HyClone, Logan, UT, USA).

\section{Tissue specimens}

Ten paired gastric tumor and adjacent non-tumor tissues, and another 10 freshly collected gastric cancer tissues were collected and histopathologically diagnosed at the Departments of Gastrointestinal Surgery and Pathology, The First Affiliated Hospital, Sun Yat-sen University. Patient consent and Institutional Research Ethics Committee approval were obtained prior to the use of these clinical materials for research purposes.

\section{Plasmids, siRNA, and transfection}

The gene for human miR-362 was PCR-amplified from genomic DNA and cloned into a pMSCV-puro retroviral vector (Clontech, Mountain View, CA). The primers used were as follows: miR-362-up, 5'-GCCAGATCTACATGC TTGGTCCCTACCC-3' and miR-362-dn, 5'-GCCCTC GAGCAGGTGCTGGATGTATTTGG-3'. The region of human CYLD 3'-UTR, generated by PCR amplification of SGC-7901 cell DNA, was cloned into pEGFP-C1 (Clontech, Mountain View, CA, USA) and pGL3 vectors (Promega, Madison, WI, USA). The primers used (forward and reverse) were as follows: CYLD-3'UTR-GFP-up, 5'-GCCCTCGAGCTTGACTCCGTTCCCCTTCAGA C-3'; CYLD-3'UTR-GFP-dn, 5'-GCCGGATCCAAC CAAGGGCAGTTGAGTC-3' and CYLD-3'UTR-luc-up, 5'-GCCCCGCGGCTCCGTTCCCCTTCAGAC-3'; CYLD3'UTR-luc-dn, 5'-GCCCTGCAGAACCAAGGGCAGTTG AGTC-3'. The siRNAs used were CYLD siRNA\#1: 5'GUACCGAAGGGAAGUAUAGUU-3' and CYLD siRNA\#2: 5'-CGCGCUGUAACUCUUUAGCAUU-3'. MiR-362 inhibitor and negative control were purchased from RiboBio (Guangzhou, Guangdong, China). Plasmid and siRNA transfection were performed using Lipofectamine 2000 (Invitrogen) according to the manufacturer's instructions.

\section{Western blotting}

Western blotting was performed according to standard methods as previously described [33] using anti-p65, antip84, anti-GFP (Cell Signaling, Danvers, MA, USA), and anti-CYLD antibodies (Abcam, Cambridge, MA, USA). The membranes were stripped and reprobed with anti- $\alpha-$ tubulin antibody (Sigma-Aldrich, Saint Louis, MO, USA) as a loading control.

\section{RNA extraction and real-time quantitative PCR}

Total miRNA from cultured cells and freshly collected gastric tissues was extracted using a mirVana miRNA 
Isolation Kit (Ambion, Austin, TX, USA) according to the manufacturer's instructions. cDNA was synthesized from 10 ng total RNA using a TaqMan miRNA Reverse Transcription Kit (Applied Biosystems, Foster City, CA, USA); Expression levels of miR-362 were quantified using a miRNA-specific TaqMan MiRNA Assay Kit (Applied Biosystems). MiRNA expression was defined based on the threshold cycle $(\mathrm{Ct})$; relative expression levels were derived using $2^{-[(\mathrm{Ct} \text { of miR-362) - (Ct of U6)] }}$ after normalization to reference U6 small nuclear RNA expression.

Total RNA was extracted from cells using TRIzol (Invitrogen) according to the manufacturer's instructions. RNA $(2 \mu \mathrm{g})$ from each sample was used for cDNA synthesis primed with random hexamers. The primers (forward and reverse) used for gene expression were: CCND1, 5' -TCCTCTCCAAAATGCCAGAG-3' and 5'GGCGGATTGGAAATGAACTT-3'; MYC, 5'-TCAAG AGGCGAACACACAAC $-3^{\prime}$ and $5^{\prime}$-GGCCTTTTCATT GTTTTCCA-3'; BCL2L1, 5'-TTCAGTGACCTGACAT CCCA-3' and 5' -CTGCTGCATTGTTCCCATAG-3'; FLIP, 5' ${ }^{\prime}$-TTTCTTTGCCTCCATCTTGG-3' and 5'-GGG GGAGTTCGTCCTGTC-3'; XIAP, 5'-GACCCTCCCCT TGGACC-3' and 5'-CTGTTAAAAGTCATCTTCTCT TGAAA-3'; TNF, 5'-CCAGGCAGTCAGATCATCTTC TC-3' and 5'-AGCTGGTTATCTCTCAGCTCCAC-3'; IL-8, $5^{\prime}$-TGCCAAGGAGTGCTAAAG- ${ }^{\prime}$ and $5^{\prime}$-CTCCA CAACCCTCTGCAC-3'; COX-2, 5'-GGCGCTCAGC CATACAG-3' and 5'-CCGGGTACAATCGCACTTAT-3'. Expression data were normalized to the geometric mean of the housekeeping gene GAPDH (forward and reverse primers: 5'-GACTCATGACCACAGTCCATGC-3' and 5'-AGAGGCAGGGATGATGTTCTG-3') to control expression level variability and were derived using

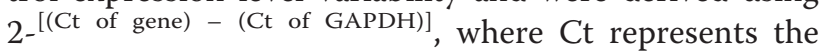
threshold cycle for each transcript.

\section{MTT assay}

Cells (2000) were seeded in 96-well plates and stained at the indicated time points with $100 \mu \mathrm{L}$ sterile MTT dye $\left(0.5 \mathrm{mg} / \mathrm{mL}\right.$, Sigma-Aldrich) for $4 \mathrm{~h}$ at $37^{\circ} \mathrm{C}$. The culture medium was removed and $150 \mu \mathrm{L}$ DMSO (Sigma-Aldrich) was added. Absorbance was measured at $570 \mathrm{~nm}$, with $655 \mathrm{~nm}$ as the reference wavelength. All experiments were performed in triplicate.

\section{Colony formation assay}

Cells (1000) were plated in 6-well plates and cultured for 10 days. Colonies were fixed with $10 \%$ formaldehyde for 5 min and stained with $1.0 \%$ crystal violet for $30 \mathrm{~s}$.

\section{Flow cytometry analysis}

Cells were harvested by trypsinization, washed in ice-cold PBS, and fixed in $80 \%$ ice-cold ethanol in PBS. Before staining, cells were pelleted using a chilled centrifuge and resuspended in cold PBS. Bovine pancreatic RNase (Sigma-Aldrich) was added to a final concentration of $2 \mu \mathrm{g} / \mathrm{mL}$ and cells were incubated at $37^{\circ} \mathrm{C}$ for $30 \mathrm{~min}$, followed by incubation with $20 \mu \mathrm{g} / \mathrm{mL}$ propidium iodide (PI, Sigma-Aldrich) for $20 \mathrm{~min}$ at room temperature. The cell cycle profiles of $5 \times 10^{4}$ cells were analyzed using a FACSCalibur flow cytometer (BD, Bedford, MA).

\section{TUNEL assay}

Apoptotic DNA fragmentation was examined using an in situ DeadEnd ${ }^{\text {tix }}$ Fluorometric Terminal Deoxynucleotidyl Transferase-Mediated dUTP Nick-End Labeling (TUNEL) System Assay Kit (Promega) according to the manufacturer's protocol. Briefly, $1 \times 10^{5}$ cells/well were plated in 24-well flat-bottom plates and treated with $20 \mu \mathrm{M}$ cisplatin for $36 \mathrm{~h}$. Cells were fixed in $4 \%$ paraformaldehyde at $4{ }^{\circ} \mathrm{C}$ for $30 \mathrm{~min}$, permeabilized in $0.1 \%$ Triton X-100, and labeled with fluorescein-12-dUTP using terminal deoxynucleotidyl transferase. The localized green fluorescence of apoptotic cells (fluorescein-12-dUTP) was detected by fluorescence microscopy (Zeiss Axiovert 100 M, Carl Zeiss, Germany).

\section{Luciferase assay}

Cells $\left(4 \times 10^{4}\right)$ were seeded in triplicate in 24-well plates and cultured for $24 \mathrm{~h}$. NF- $\mathrm{kB}$ reporter luciferase plasmid (100 ng), pGL3-CYLD-3'UTR (wt/mut), or control luciferase plasmid, plus 5 ng pRL-TK Renilla plasmid (Promega) was transfected into the cells using Lipofectamine 2000 (Invitrogen) according to the manufacturer's recommendations. Luciferase and Renilla signals were measured $36 \mathrm{~h}$ after transfection using a Dual Luciferase Reporter Assay Kit (Promega) according to the manufacturer's protocol.

\section{Nuclear/cytoplasmic fractionation}

Cells were washed with cold PBS and resuspended in buffer containing $10 \mathrm{mM}$ HEPES (pH 7.8), $10 \mathrm{mM} \mathrm{KCl}$, $0.1 \mathrm{mM}$ EDTA, $1 \mathrm{mM} \mathrm{Na} \mathrm{VO}_{4}, 1 \mathrm{mM}$ DTT, 1:500 protease inhibitors (Sigma-Aldrich), and $0.2 \mathrm{mM}$ PMSF and incubated on ice for $15 \mathrm{~min}$. Detergent was added and cells were vortexed for $10 \mathrm{~s}$ at the highest setting. Nuclei were separated by centrifugation at $4^{\circ} \mathrm{C}$, resuspended in buffer containing $20 \mathrm{mM}$ HEPES (pH 7.8), 0.4 M NaCl, $1 \mathrm{mM}$ EDTA, $1 \mathrm{mM} \mathrm{Na} \mathrm{VO}_{4}, 1 \mathrm{mM}$ DTT, and 1:500 protease inhibitors, and incubated on ice for $15 \mathrm{~min}$. Nuclear extracts were collected by centrifugation at $14,000 \times g$ for $10 \mathrm{~min}$ at $4^{\circ} \mathrm{C}$.

\section{Annexin $\mathrm{V}$ binding assay}

An ApopNexin ${ }^{\text {Tx }}$ FITC Apoptosis Detection Kit (Millipore, Lake Placid, NY, USA) was used to detect apoptotic cells according to the manufacturer's instructions. Cells $\left(3 \times 10^{5}\right)$ were seeded in 6-well plates in triplicate and incubated with 
$20 \mu \mathrm{M}$ cisplatin or vehicle for 24 hours. Adherent and floating cells were combined, followed by washing with PBS and then with annexin $\mathrm{V}$ binding solution. Subsequently, $150 \mu \mathrm{L}$ annexin $\mathrm{V}$ antibody in binding buffer was added to each well and incubated for $15 \mathrm{~min}$, followed by the addition of $1.5 \mu \mathrm{L} 1 \mathrm{mg} / \mathrm{mL}$ PI and further incubation for 5 min. Cells $(10,000)$ were analyzed using a FACSCalibur flow cytometer (BD Biosciences). The data were analyzed with CellQuest software to differentiate apoptotic cells (annexin V-positive and PI-negative) from necrotic cells (including late apoptotic cells).

\section{Statistical analysis}

A two-tailed Student's $t$-test was used to evaluate the significance of the differences between two groups of data in all pertinent experiments; $P<0.05$ was considered significant.

\section{Results}

MiR-362 was upregulated in human gastric cancer cell lines and tissues

To identify miRNAs that may be involved in gastric cancer progression, we analyzed a published microarray-based, high-throughput miRNA expression dataset (E-TABM341, ArrayExpress). We found that miR-362 expression was significantly upregulated in human gastric cancer tissues $(\mathrm{n}=184)$ than that in normal gastric tissues $(\mathrm{n}=169)$ $(P<0.001$, Figure 1A). Real-time PCR analysis showed marked upregulation of miR-362 expression in all five gastric cancer cell lines as compared with that in NGEC (Figure 1B). Comparative analysis indicated that miR-362 was increased in all 10 gastric tumor tissue specimens as compared with adjacent non-cancerous tissue specimens (Figure 1C). Taken together, these results demonstrate that miR-362 is upregulated in human gastric cancer.

\section{MiR-362 upregulation promoted cell proliferation and induced apoptosis resistance in gastric cancer}

To investigate the biological effect of miR-362 upregulation on gastric cancer progression, the $\mathrm{BGC}-823$ and SGC-7901 gastric cancer cell lines were used to stably express miR-362. MTT assay showed that miR-362 upregulation significantly increased the rate of cell proliferation (Figure 2A), and this was confirmed by colony formation assay (Figure 2B). Flow cytometry revealed a dramatic
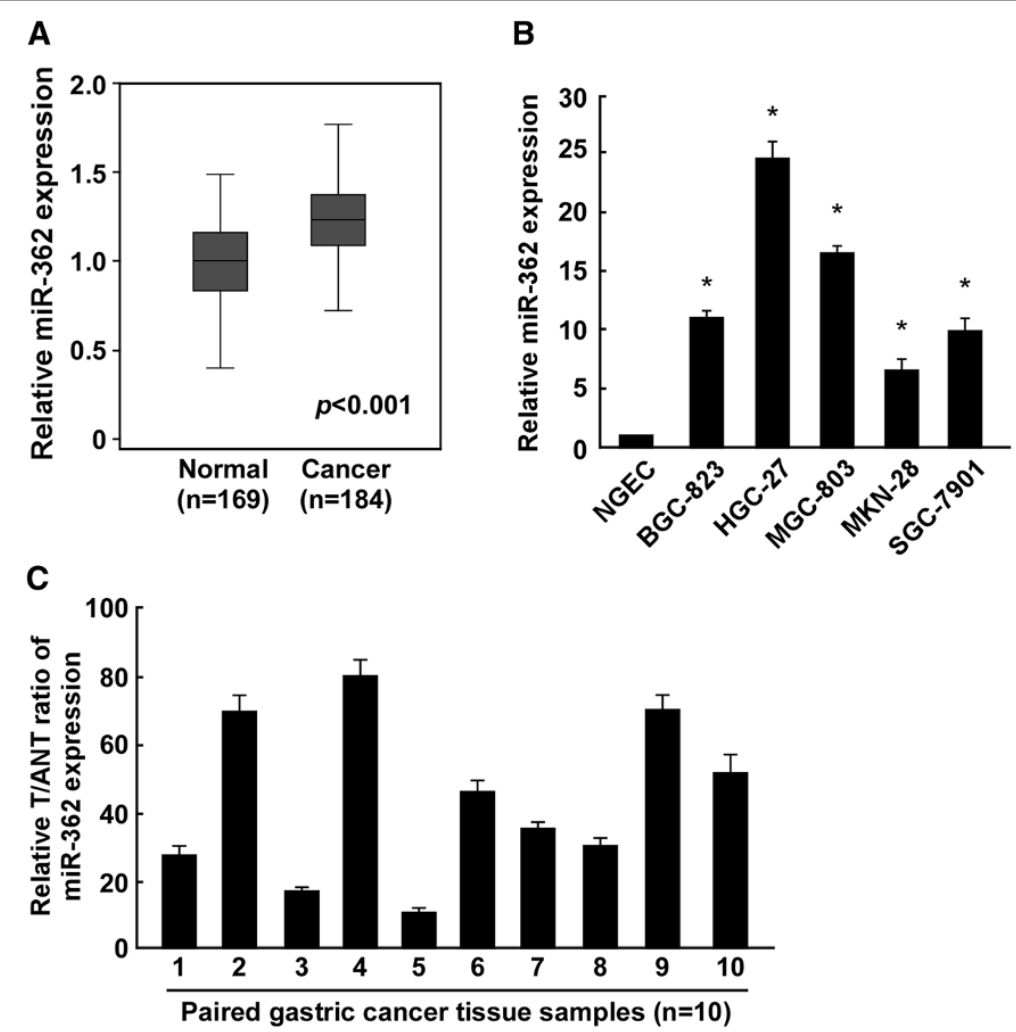

Figure 1 MiR-362 upregulation in human gastric cancer cell lines and tissues. (A) High-throughput microarray analysis of published data showing that miR-362 was elevated in gastric cancer tissues $(n=184)$ as compared with that in noncancerous gastric tissue $(n=169)$. (B) Real-time PCR analysis of miR-362 expression in NGEC and gastric cancer BGC-823, HGC-27, MGC-803, MKN-28, and SGC-7901 cell lines. Transcript levels were normalized to U6 expression. (C) MiR-362 expression in primary gastric cancer tissues (T) with paired adjacent normal tissues (ANT) from 10 patients. Transcript levels were normalized to U6 expression. Experiments B and C were repeated at least three times. Bars denote the mean of three independent experiments. ${ }^{*} P<0.05$ 


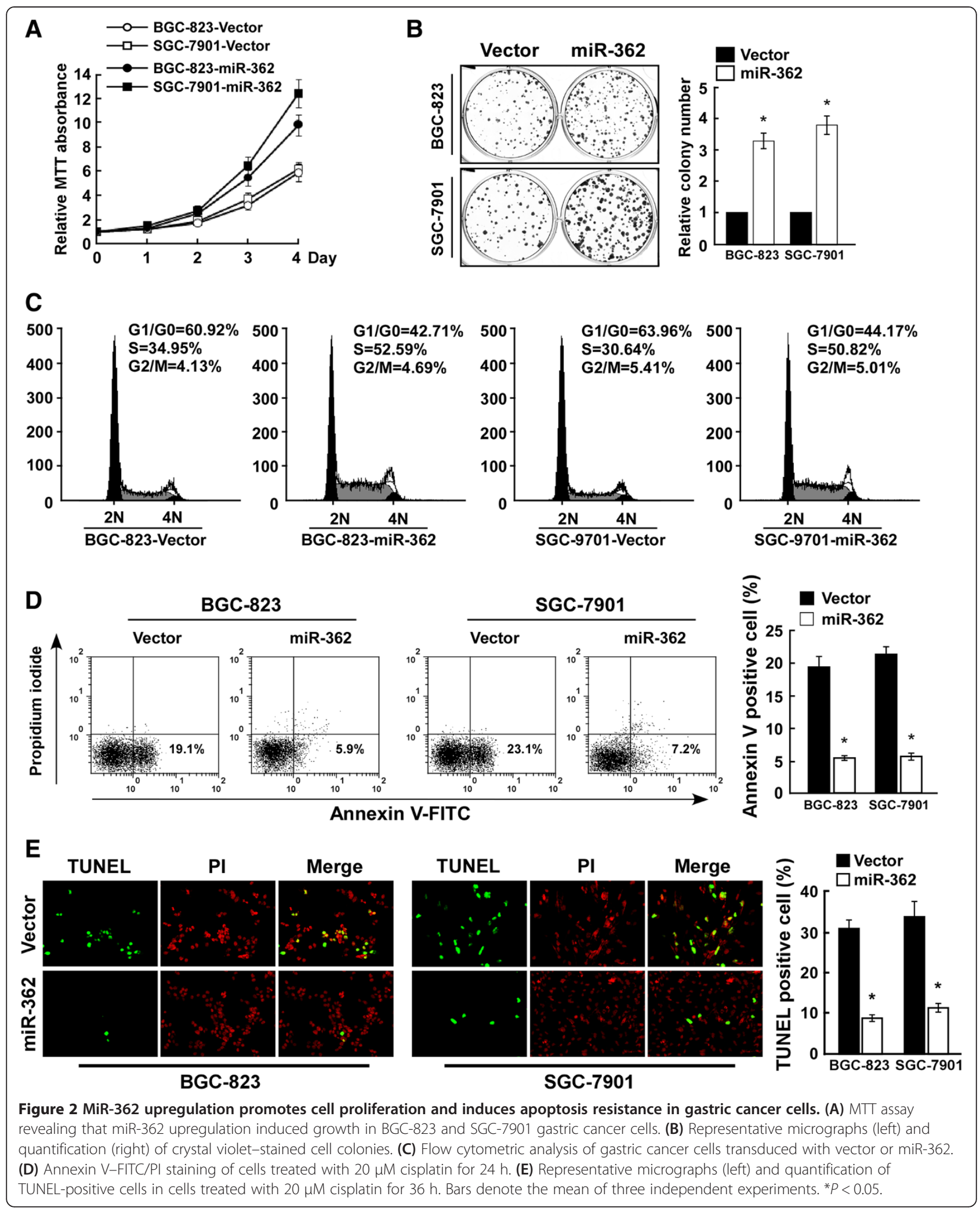


increase in the percentage of S-phase cells in miR-362overexpressing BGC-823 (52.59\%) and SGC-7901 cells (50.82\%) as compared with control BGC-823 (34.95\%) and SGC-7901 cells (30.64\%), respectively (Figure 2C). Annexin $\mathrm{V}$ and TUNEL staining (Figure 2D and 2E) demonstrated that miR-362 overexpression augmented the resistance of gastric cancer cells to apoptosis induced by the cisplatin treatment. These results suggest that miR-362 plays an oncogenic role in gastric cancer cells in vitro.

\section{MiR-362 inhibition reduced cell proliferation and induced apoptosis in human gastric cancer}

We examined the effect of miR-362 inhibition on gastric cancer progression. Consistent with the above results, the MTT and colony formation assays showed that miR-362 suppression dramatically inhibited the growth rate of both BGC-823 and SGC-7901 cells as compared with that of control cells (Figure 3A and 3B). Flow cytometry showed that miR-362 inhibition decreased the percentage of cells in S-phase peak but increased that of G1/G0-phase cells (Figure 3C), suggesting that miR-362 inhibition results in G1/S arrest in gastric cancer cells. Annexin V and TUNEL staining demonstrated that miR-362 inhibition decreased resistance to apoptosis in cisplatin-treated gastric cancer cells (Figure 3D and 3E).

\section{MiR-362 activated the NF-кB pathway}

We investigated the underlying molecular mechanism that might be responsible for the oncogenic roles of miR-362. As the NF- $\mathrm{kB}$ signaling pathway is frequently found hyperactivated in gastric tumors [11,34,35], and activation of NF- $\mathrm{kB}$ signaling induces cell proliferation and apoptosis resistance [36], we investigated whether miR-362 regulated NF- $\mathrm{kB}$ activity. NF- $\mathrm{kB}$ reporter luciferase activity and the expression levels of the eight NF- $\mathrm{kB}$ target genes were significantly increased in miR-362-overexpressing cells, but were decreased in cells in which miR-362 had been inhibited (Figure 4A and 4B). Though miR-362 had no effect on the total NF-kB/p65 protein expression, cellular fractionation and immunofluorescence staining showed that miR-362 overexpression promoted nuclear accumulation of $\mathrm{NF}-\mathrm{kB} / \mathrm{p} 65$, while miR-362 inhibition reduced nuclear NF-kB/p65 expression (Figure 4C and 4D), indicating that miR-362 activates the NF- $\kappa B$ pathway through promotion of nuclear NF- $\kappa B$ accumulation. Inhibition of NF- $\mathrm{kB}$ signaling by the transfection of an $I \kappa B \alpha$ dominant-negative mutant led to a dramatic decrease in S-phase peak cells but increased the G0/G1-phase peak population (Figure 4E) and cisplatin sensitivity in miR-362-overexpressing cells (Figure 4F), suggesting that NF- $\mathrm{kB}$ pathway activation is functionally relevant to miR-362-mediated proliferation and antiapoptosis.

\section{MiR-362 targeted CYLD directly}

CYLD deubiquitinase is a key negative regulator of NF- $\mathrm{kB}$ signaling [21-23]. Analysis using publicly available algorithms (TargetScan, PicTar, miRanda) showed that CYLD is a potential target of miR-362 (Figure 5A). Western blotting analysis revealed that CYLD expression was dramatically repressed by miR-362 overexpression, or induced by miR-362 inhibition (Figure 5B). To examine whether miR-362-induced CYLD downregulation was mediated by the CYLD 3 '-UTR, we subcloned the CYLD 3'-UTR fragment containing the miR-362 binding site into pEGFP-C1 and pGL3 dual luciferase reporter vectors. MiR-362 overexpression only decreased the expression of the GFP vector containing the CYLD 3 '-UTR (Figure 5C), but had no effect on GFP- $\gamma$-tubulin expression, suggesting that miR-362 specifically affected the CYLD 3'-UTR. Reduced luciferase activity was observed following miR362 overexpression in both BGC-823 and SGC-7901 cells, whereas the repressive effect of miR-362 on luciferase activity of the CYLD 3'-UTR was abolished by the miR-362 inhibitor (Figure 5D). MiR-362 overexpression had no effect on the luciferase activity of CYLD-3'UTR-mut, which contained point mutations in the miR-362-binding seed region of the CYLD 3'-UTR (Figure 5E). Collectively, our results demonstrate that CYLD is a bona fide target of miR-362.

\section{CYLD downregulation is critical for miR-362-mediated NF-KB activation}

To further investigate the role of CYLD repression in miR-362-mediated NF- $\mathrm{B}$ B activation, we examined the effects of CYLD downregulation on NF- $\mathrm{BB}$ activation in BGC-823 and SGC-7901 cells. As expected, CYLD knockdown by the two CYLD-specific siRNAs significantly increased NF- $\mathrm{B}$ reporter luciferase activity and the expression levels of the eight NF- $\mathrm{KB}$ target genes (Figure 5F and Additional file 1: Figure S1A). However, further miR-362 overexpression in the CYLD-silenced cells did not have a significant additive effect on NF- $\mathrm{KB}$ reporter luciferase activity nor NF- $\mathrm{kB}$ target genes expression (Figure 5F and Additional file 1: Figure S1A). Importantly, CYLD downregulation abolished the miR362 inhibition that induced repression of NF- $\mathrm{kB}$ activity and target gene expression (Figure 5G and Additional file 1: Figure S1B). Overall, our results demonstrate that CYLD plays an important role in miR-362-mediated NF- $\mathrm{kB}$ activation.

\section{Clinical correlation between miR-362, CYLD expression, and NF-KB activation in gastric cancer tissues}

We investigated whether the miR-362-induced CYLD repression and NF- $\mathrm{B}$ activation were clinically relevant. MiR-362 levels in the 10 freshly collected gastric cancer specimens were inversely correlated with CYLD expression 


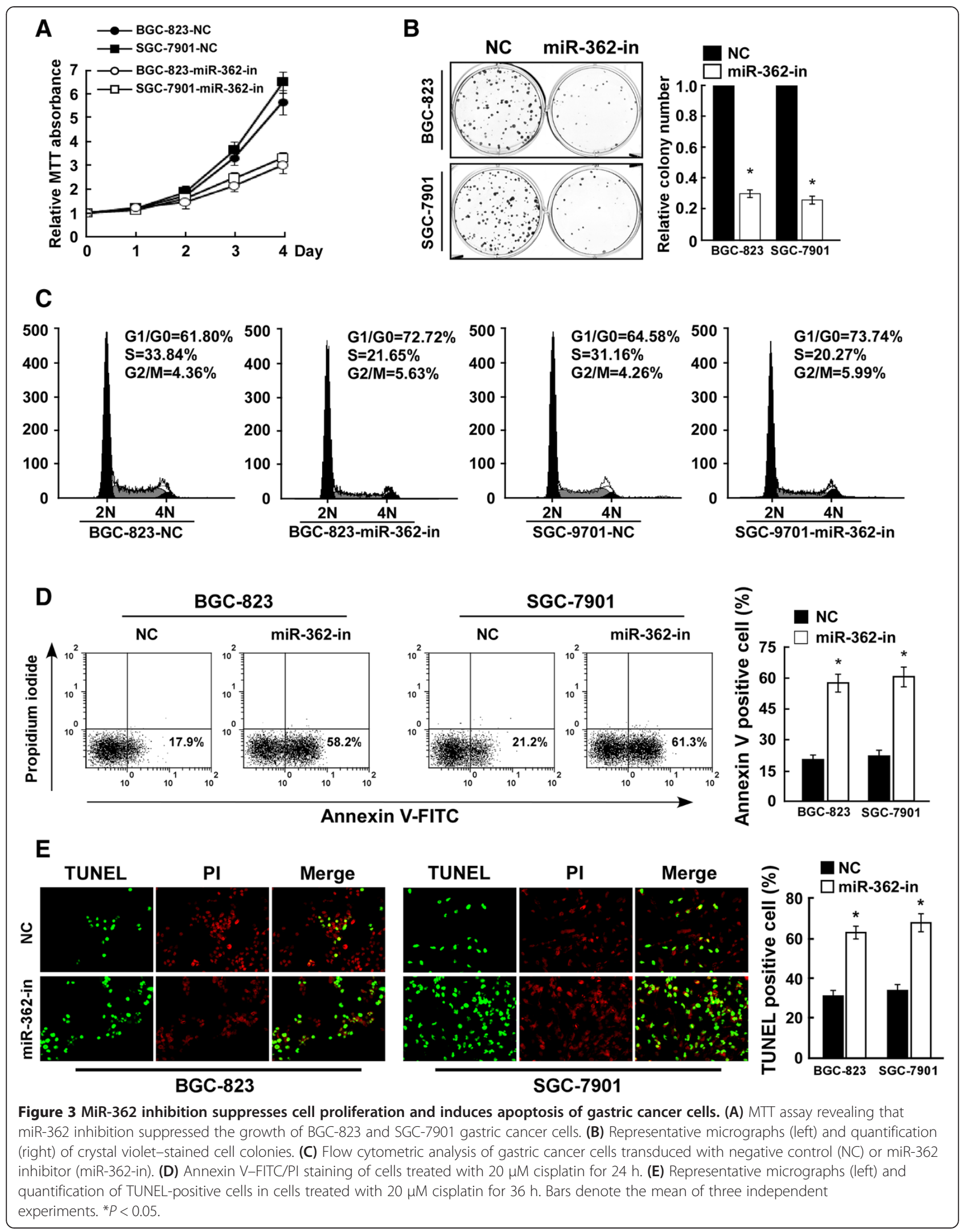




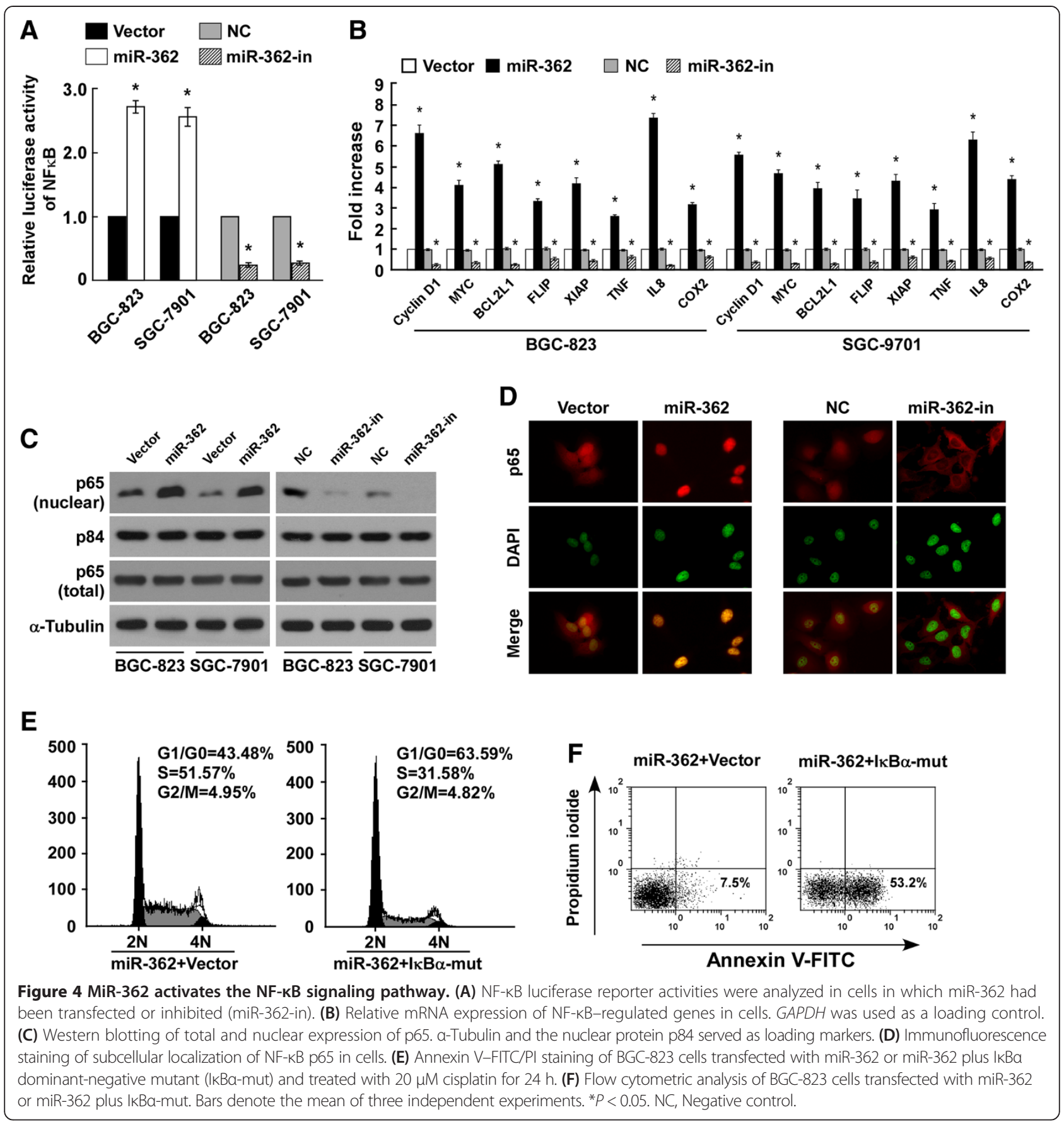

levels $(r=-0.796, P<0.001$; Figure 6 ) but positively correlated with nuclear p65 expression $(r=0.670, P=0.034)$. Altogether, our results suggest that miR-362 upregulation activates NF- $\mathrm{BB}$ signaling by repressing CYLD, consequently leading to cell proliferation and apoptosis resistance in gastric cancer.

\section{Discussion}

MiRNAs are small noncoding RNAs that regulate the expression of a large number of intracellular target genes.
Overexpression of certain miRNAs are important in the regulation of cell proliferation, apoptosis, and differentiation in gastric cancer [37-39]. In the present study, miR362 expression was upregulated in gastric cancer tissues and cell lines. This is the first study to report that miR362 overexpression or inhibition with lentivirus vector in BGC-823 and SGC-7901 cells regulated NF-kB activity, p65 protein level, and expression of the NF-kB-related target genes CCND1, MYC, BCL2L1, FLIP, XIPA, TNF, $I L-8$, and $C O X-2$. Luciferase assay confirmed that miR-362 


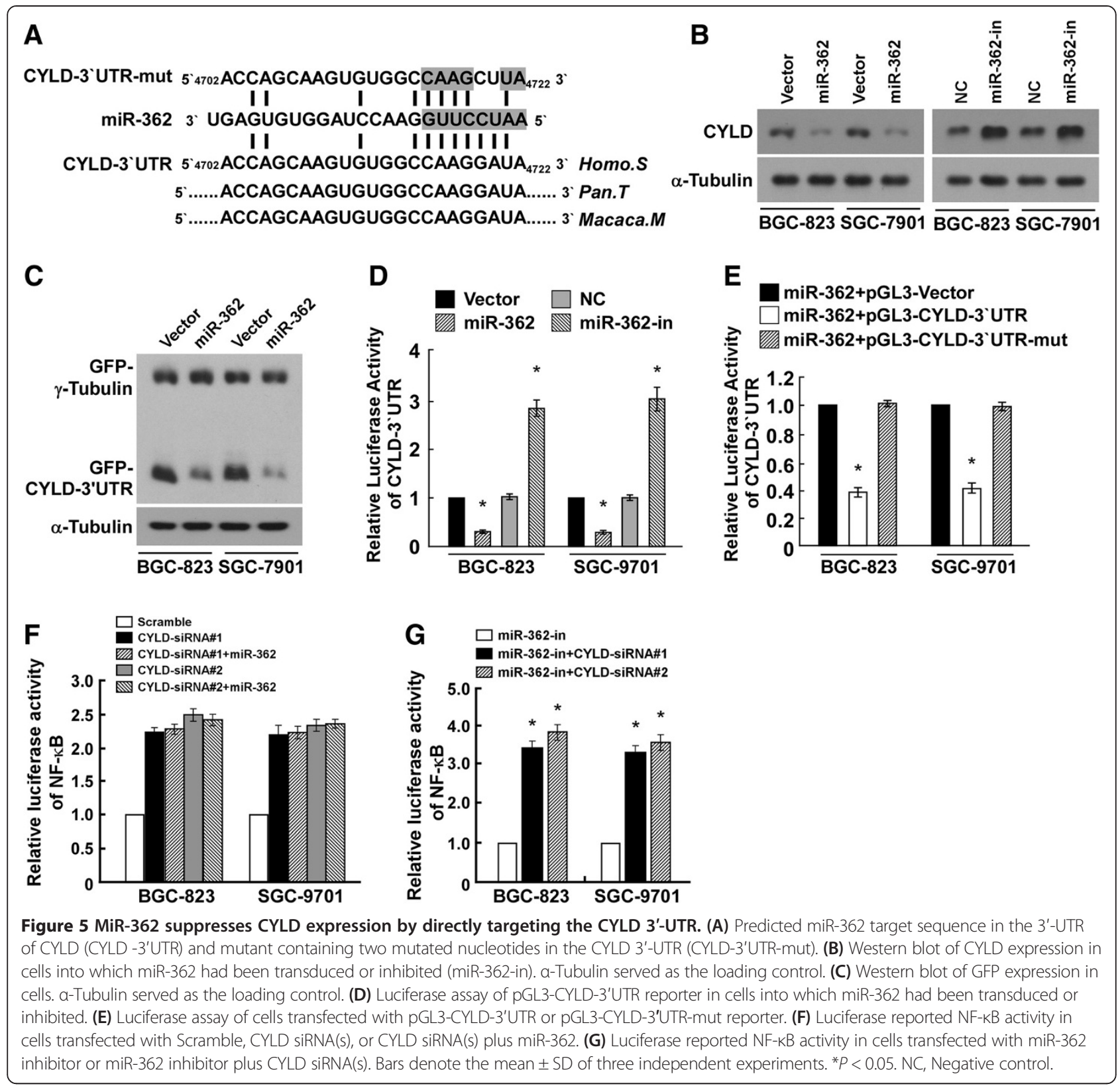

directly binds the 3 '-UTR of CYLD mRNA and inhibits CYLD translation in gastric cancer cells.

The tumor suppressor CYLD is downregulated in many types of cancer, including gliomas, basal cell carcinoma, melanoma, T-cell leukemia, and colon and hepatocellular carcinomas [20,40-43]. Several mechanisms have been proposed to mediate CYLD downregulation in cancers. In skin cancers such as basal cell carcinoma and melanoma, CYLD was repressed at the transcriptional level by the activation of Snail $[40,41]$. Conversely, CYLD expression in T-cell leukemia was regulated by transcriptional repression by Hes1 [42]. Importantly, a recent study reported that CYLD is a direct target of miR-182, the increased expression of which resulted in CYLD reduction and sustained NF- $\mathrm{kB}$ activation in gliomas [20]. In the present study, miR-362 directly targeted CYLD and led to cell proliferation and apoptosis resistance, which we believe is a novel mechanism for reducing CYLD in gastric cancer.

It is widely reported that NF- $\mathrm{kB}$ activation is associated with gastric chronic inflammation and gastric cancer [44-46]. NF- $\mathrm{B}$ activation is required for IL-8 release and COX-2 activation, both of which induce the expression of plasminogen activator inhibitor 2 in inflammation caused by Helicobacter pylori infection [44]. In gastric cancer, plumbagin inhibits cell growth and enhances apoptosis through suppression of the NF-kB pathway [34]. 

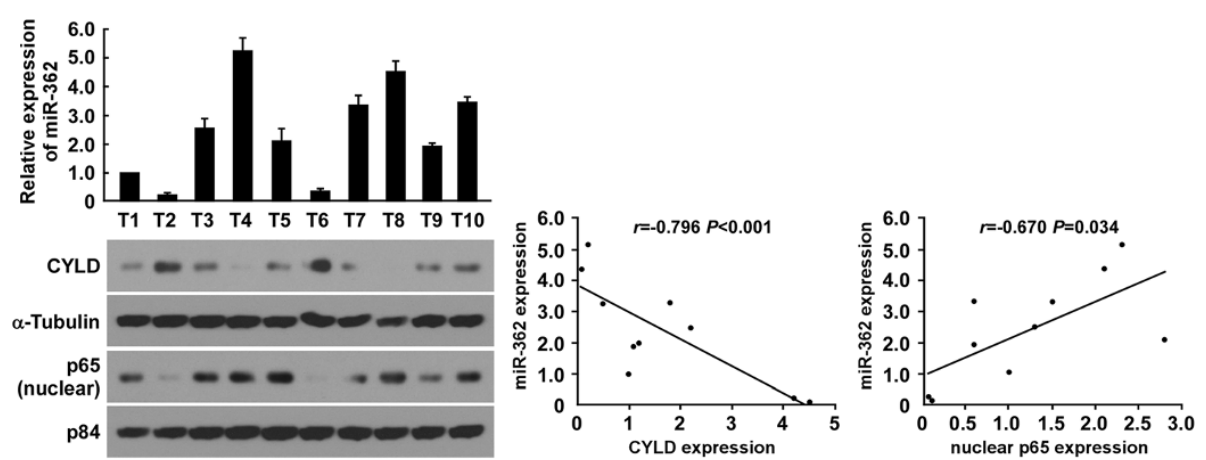

Figure 6 MiR-362 expression inversely correlates with CYLD expression in gastric cancer tissues. Analysis (left) and correlation (right) between miR-362 expression and CYLD and nuclear p65 expression levels in 10 freshly collected human gastric cancer tissue specimens. a-Tubulin and the nuclear protein p84 were used as loading controls. Bars denote the mean \pm SD of three independent experiments.

Furthermore, miR-372 promotes cell growth and inhibits apoptosis through TNFAIP1 downregulation and inhibition of the NF-kB pathway [46]. However, the mechanism of NF- $\mathrm{KB}$ activation in gastric cancer remains unclear. In the present study, miR-362 directly targeted the CYLD mRNA 3'-UTR and inhibited CYLD translation. The reduction of CYLD ultimately resulted in NF- $\mathrm{kB}$ activation. Moreover, as CYLD can be transcriptionally induced by the NF-kB pathway in a negative feedback pathway [47], we may have uncovered a mechanism that leads to persistent NF- $\mathrm{B}$ activation in gastric cancer.

Over the years, adjuvant and neoadjuvant chemotherapy have been taken into account in the treatment strategy for gastric cancer $[4,5]$. However, the curative effects of chemotherapy in gastric cancer patients are debatable, due to the loss of sensitivity to chemo-induced apopotosis [6]. There is an urgent need to identify an effective parameter that can predict the response to chemotherapy and assist the establishment of individualized therapeutic strategies for gastric cancer patients. Our results suggest that miR-362 overexpression in gastric cancer enhanced cell proliferation and resistance to cisplatininduced apoptosis in gastric cancer cells. This suggests that miR-362 levels may affect a patient's sensitivity to chemotherapy. MiR-362 may serve as a predictive factor of patient response towards chemotherapy and may aid in the selection of the optimal therapeutic strategy for gastric cancer patients.

In the present study, miR-362 inhibition decreased cell proliferation, induced apoptosis, and decreased nuclear translocation of p65. This suggests that miR-362 activates the NF-kB pathway without any feedback effect, resulting in persistent NF- $\mathrm{B}$ activation. Although recent discoveries have noted the important roles of many miRNAs in carcinogenesis and cancer progress, data on how miR-362 functions and how it is regulated are scant. In the present study, we identified a very important relationship between miR-362 and NF-kB. As an upstream regulator of the NF-kB pathway, miR-362 downregulation may play an important role in NF- $\mathrm{B}$ pathway suppression.

It was reported that blocking the NF- $\mathrm{B}$ pathway using an $\mathrm{I} \kappa \mathrm{B} \alpha$ super-repressor such as TNF- $\alpha$ enhances the susceptibility of cells to apoptosis [48]. NF- $\kappa B$ inhibitors enhance the chemotherapeutic sensitivity of colon cancer cells [49]. However, an IкB inhibitor could not block the NF- $\mathrm{kB}$ pathway for a prolonged period [48]. Lack of specificity and potential side effects are the major issues in NF- $\mathrm{kB}$ inhibitor treatment strategies [50]. Our study presents a new possibility for improving the prognosis of gastric cancer patients with the therapeutic effects of miR-362 inhibition through CYLD downregulation and persistent decrease of NF- $\mathrm{KB}$ activity.

\section{Additional file}

Additional file 1: CYLD plays an important role in miR-362-mediated NF-KB activaton.

\section{Abbreviations}

CYLD: Cylindromatosis; NF-kB: Nuclear factor KB; Bcl211: BCL2-like 1; Cox-2: Cytochrome c oxidase subunit II; IL-8: Interleukin 8; TNF: Tumor necrosis factor; XIAP: X-linked inhibitor of apoptosis; FLIP: FLICE-inhibitory protein.

\section{Competing interests}

The authors have declared that no competing interest exists.

\section{Authors' contributions}

JTX, LZC and WHJ conducted construction of plasmids, cell culture and Western blotting analyses, Real-time PCR analysis and Luciferase assay experiments. KBW, YZY and WLH conducted Flow cytometry analysis, TUNEL assay and immunofluorescence. YLH, WL and DC supervised the project and carried out experimental design and participated in analysis of experiments data. All authors read and approved the final manuscript.

\section{Acknowledgments}

This study was supported by grants from the National Natural Science Foundation of China (No. 81172337, 30973395),and Municipal Medicine Science and Technology Foundation of Guangzhou grant (No. 201102A212012) 


\section{Author details}

'Department of General Surgery, The third Affiliated Hospital, Guangzhou Medical University, \#63 Duobao Road, Guangzhou, Guangdong 510150, China. ${ }^{2}$ Laboratory of General Surgery, The First Affiliated Hospital, Sun Yat-sen University, \#58 Zhongshan er Road, Guangzhou, Guangdong 510080, China. ${ }^{3}$ Department of General Surgery, Guangzhou First Municipal People's Hospital, Guangzhou Medical University, Guangzhou, Guangdong 510180, China. ${ }^{4}$ Department of Gastrointestinal Surgery, The First Affiliated Hospital, Sun Yat-sen University, Guangzhou, Guangdong 510080, China.

Received: 9 December 2013 Accepted: 30 January 2014 Published: 5 February 2014

\section{References}

1. Roder DM: The epidemiology of gastric cancer. Gastric Cancer 2002, 5:5-11.

2. Gallo A, Cha C: Updates on esophageal and gastric cancers. World J Gastroenterol 2006, 12:3237-3242.

3. Gunderson LL: Gastric cancer-patterns of relapse after surgical resection. Semin Radiat Oncol 2002, 12:150-161.

4. Cunningham D, Allum WH, Stenning SP, et al: Perioperative chemotherapy versus surgery alone for resectable gastroesophageal cancer. $N$ Engl J Med 2006, 355:11-20.

5. Bang YJ, Kim YW, Yang HK, et al: Adjuvant capecitabine and oxaliplatin for gastric cancer after D2 gastrectomy (CLASSIC): a phase 3 open-label, randomised controlled trial. Lancet 2012, 379:315-321.

6. Harewood GC: Treatment of gastric cancer. N Engl J Med 2006, 355:1386. author reply 1387-1388.

7. Mesner PW Jr, Budihardjo II, Kaufmann SH: Chemotherapy-induced apoptosis. Adv Pharmacol 1997, 41:461-499.

8. Kaufmann SH, Earnshaw WC: Induction of apoptosis by cancer chemotherapy. Exp Cell Res 2000, 256:42-49.

9. Hannun YA: Apoptosis and the dilemma of cancer chemotherapy. Blood 1997, 89:1845-1853.

10. Pacifico F, Leonardi A: NF-kappaB in solid tumors. Biochem Pharmaco 2006, 72:1142-1152.

11. Greten FR, Eckmann L, Greten TF, et al: IKKbeta links inflammation and tumorigenesis in a mouse model of colitis-associated cancer. Cell 2004, 118:285-296.

12. Baldwin AS: Control of oncogenesis and cancer therapy resistance by the transcription factor NF-kappaB. J Clin Invest 2001, 107:241-246.

13. Karin M: Nuclear factor-kappaB in cancer development and progression. Nature 2006, 441:431-436.

14. Kasibhatla S, Brunner T, Genestier L, Echeverri F, Mahboubi A, Green DR: DNA damaging agents induce expression of Fas ligand and subsequent apoptosis in T lymphocytes via the activation of NF-kappa B and AP-1. Mol Cell 1998, 1:543-551

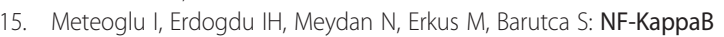
expression correlates with apoptosis and angiogenesis in clear cell renal cell carcinoma tissues. J Exp Clin Cancer Res 2008, 27:53.

16. Wertz IE, Dixit VM: Signaling to NF-kappaB: regulation by ubiquitination. Cold Spring Harb Perspect Biol 2010, 2:a003350.

17. Liu S, Chen ZJ: Expanding role of ubiquitination in NF-kappaB signaling Cell Res 2011, 21:6-21.

18. Tokunaga F, Sakata S, Saeki Y, et al: Involvement of linear polyubiquitylation of NEMO in NF-kappaB activation. Nat Cell Biol 2009, 11:123-132.

19. Düwel M, Hadian K, Krappmann D: Ubiquitin conjugation and deconjugation in NF-kappaB Signaling. Subcell Biochem 2010, 54:88-99.

20. Song $L$, Liu L, Wu Z, et al: TGF-beta induces miR-182 to sustain NF-kappaB activation in glioma subsets. J Clin Invest 2012, 122:3563-3578.

21. Kovalenko A, Chable-Bessia C, Cantarella G, Israël A, Wallach D, Courtois G: The tumour suppressor CYLD negatively regulates NF-kappaB signalling by deubiquitination. Nature 2003, 424:801-805.

22. Trompouki E, Hatzivassiliou E, Tsichritzis T, Farmer $H$, Ashworth A, Mosialos G: CYLD is a deubiquitinating enzyme that negatively regulates NF-kappaB activation by TNFR family members. Nature 2003, 424:793-796.

23. Sun SC: CYLD: a tumor suppressor deubiquitinase regulating NF-kappaB activation and diverse biological processes. Cell Death Differ 2010, $17: 25-34$
24. Brummelkamp TR, Nijman SM, Dirac AM, Bernards R: Loss of the cylindromatosis tumour suppressor inhibits apoptosis by activating NF-kappaB. Nature 2003, 424:797-801

25. Massoumi R, Chmielarska K, Hennecke K, Pfeifer A, Fässler R: Cyld inhibits tumor cell proliferation by blocking Bcl-3-dependent NF-kappaB signaling. Cell 2006, 125:665-677.

26. Urbanik T, Köhler BC, Boger RJ, et al: Down-regulation of CYLD as a trigger for NF-kappaB activation and a mechanism of apoptotic resistance in hepatocellular carcinoma cells. Int J Oncol 2001 38:121-131.

27. Lee YS, Dutta A: MicroRNAs in cancer. Annu Rev Pathol 2009, 4:199-227.

28. Ueda T, Volinia S, Okumura $H$, et al: Relation between microRNA expression and progression and prognosis of gastric cancer: a microRNA expression analysis. Lancet Oncol 2010, 11:136-146.

29. Guo J, Miao Y, Xiao B, et al: Differential expression of microRNA species in human gastric cancer versus non-tumorous tissues. J Gastroenterol Hepatol 2009, 24:652-657.

30. Xia L, Zhang D, Du R, et al: miR-15b and miR-16 modulate multidrug resistance by targeting $\mathrm{BCL} 2$ in human gastric cancer cells. Int J Cancer 2008, 123:372-379

31. Chan E, Patel R, Nallur $S$, et al: MicroRNA signatures differentiate melanoma subtypes. Cell Cycle 2011, 10:1845-52.

32. Smoot DT, Sewchand J, Young K, Desbordes BC, Allen CR, Naab T: A method for establishing primary cultures of human gastric epithelial cells. Methods Cell Sci 2000, 22:133-136.

33. Li J, Zhang N, Song LB, et al: Astrocyte elevated gene-1 is a novel prognostic marker for breast cancer progression and overall patient survival. Clin Cancer Res 2008, 14:3319-3326.

34. Li J, Shen L, Lu FR, et al: Plumbagin inhibits cell growth and potentiates apoptosis in human gastric cancer cells in vitro through the NF-kappaB signaling pathway. Acta Pharmacol Sin 2012, 33:242-249.

35. Sasaki N, Morisaki T, Hashizume K, et al: Nuclear factor-kappaB p65 (RelA) transcription factor is constitutively activated in human gastric carcinoma tissue. Clin Cancer Res 2001, 7:4136-4142.

36. Camp ER, Li J, Minnich DJ, et al: Inducible nuclear factor-kappaB activation contributes to chemotherapy resistance in gastric cancer. J Am Coll Surg 2004, 199:249-258

37. Nishizawa T, Suzuki H: The Role of microRNA in Gastric Malignancy. Int J Mol Sci 2013, 14:9487-9496.

38. Oin S, Ai F, Ji WF, Rao W, Zhang HC, Yao WJ: miR-19a promotes cell growth and tumorigenesis through targeting SOCS1 in gastric cancer. Asian Pac J Cancer Prev 2013, 14:835-840.

39. Yang SM, Huang C, Li XF, Yu MZ, He Y, Li J: miR-21 confers cisplatin resistance in gastric cancer cells by regulating PTEN. Toxicology 2013, 306:162-168.

40. Kuphal S, Shaw-Hallgren G, Eberl M, Karrer S, et al: GLI1-dependent transcriptional repression of CYLD in basal cell carcinoma. Oncogene 2011, 30:4523-4530

41. Massoumi R, Kuphal S, Hellerbrand C, et al: Down-regulation of CYLD expression by Snail promotes tumor progression in malignant melanoma. J Exp Med 2009, 206:221-232.

42. Espinosa L, Cathelin S, D'Altri T, et al: The Notch/Hes1 pathway sustains NF-kappaB activation through CYLD repression in T cell leukemia. Cancer Cell 2010, 18:268-281.

43. Hellerbrand C, Bumes E, Bataille F, Dietmaier W, Massoumi R, Bosserhoff AK: Reduced expression of CYLD in human colon and hepatocellular carcinomas. Carcinogenesis 2007, 28:21-27.

44. Varro A, Noble PJ, Pritchard DM, et al: Helicobacter pylori induces plasminogen activator inhibitor 2 in gastric epithelial cells through nuclear factor-kappaB and RhoA: implications for invasion and apoptosis. Cancer Res 2004, 64:1695-1702.

45. Chiba T, Marusawa $H$, Matsumoto $Y$, Takai A: Chronic inflammation and gastric cancer development. Nihon Rinsho 2012, 70:1694-1698.

46. Zhou C, Li X, Zhang $X$, et al: microRNA-372 maintains oncogene characteristics by targeting TNFAIP1 and affects NFkappaB signaling in human gastric carcinoma cells. Int J Oncol 2013 42:635-642

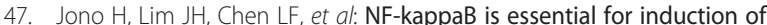
CYLD, the negative regulator of NF-kappaB: evidence for a novel inducible autoregulatory feedback pathway. J Biol Chem 2004, 279:36171-36174. 
48. Wang CY, Mayo MW, Baldwin AS Jr: TNF- and cancer therapy-induced apoptosis: potentiation by inhibition of NF-kappaB. Science 1996, 274:784-787.

49. Liu T, Liu D, Liu J, et al: Effect of NF-kappaB inhibitors on the chemotherapy-induced apoptosis of the colon cancer cell line HT-29. Exp Ther Med 2012, 4:716-722.

50. Yamamoto Y, Gaynor RB: Therapeutic potential of inhibition of the NF-kappaB pathway in the treatment of inflammation and cancer. J Clin Invest 2001, 107:135-142.

doi:10.1186/1479-5876-12-33

Cite this article as: Xia et al:: MicroRNA-362 induces cell proliferation and apoptosis resistance in gastric cancer by activation of NF-KB signaling. Journal of Translational Medicine 2014 12:33.

\section{Submit your next manuscript to BioMed Central and take full advantage of:}

- Convenient online submission

- Thorough peer review

- No space constraints or color figure charges

- Immediate publication on acceptance

- Inclusion in PubMed, CAS, Scopus and Google Scholar

- Research which is freely available for redistribution 